\title{
A population-based study of Kaposi Sarcoma- associated herpesvirus seropositivity in Uganda using principal components analysis
}

\author{
Joanne T Chang ${ }^{1,3^{*}}$, Fatma M Shebl ${ }^{1,4}$, Ruth M Pfeiffer ${ }^{1}$, Benon Biryahwaho², Barry I Graubard ${ }^{1}$ \\ and Sam M Mbulaiteye ${ }^{1}$
}

\begin{abstract}
Background: Kaposi sarcoma-associated herpesvirus (KSHV) seropositivity is associated with sexual, environmental, and socioeconomic exposures. Whether these characteristics are independent risk factors is uncertain because of reliance on selected high-risk or hospital-based populations and incomplete adjustment for confounding. Therefore, we evaluated risk factors for KSHV seropositivity in a population-based study in Uganda using principal components analysis (PCA).

Methods: The study population comprised 2,681 individuals randomly selected from a nationally-representative population-based HIV/AIDS sero-behavioral survey conducted in 2004/05. Questionnaire and laboratory data (97 variables) were transformed into a smaller set of uncorrelated variables using PCA. Multivariable logistic regression models were fitted to estimate odds ratios and 95\% confidence intervals for the association between components and KSHV seropositivity.
\end{abstract}

Results: Data were reduced to three principal components (PCs) labeled as Sexual behavioral, Socioeconomic, and Knowledge PCs. In crude analysis, KSHV seropositivity was associated with the Knowledge $\left(p_{\text {trend }}=0.012\right)$ and Socioeconomic components ( $\left.p_{\text {trend }}=0.0001\right)$, but not with the Sexual-behavioral component $\left(p_{\text {trend }}=0.066\right)$. KSHV seropositivity was associated with the Socioeconomic PC ( $\left.p_{\text {trend }}=0.037\right)$, but not with the Sexual-behavioral and Knowledge PCs, in the models including PCs, age, gender and geographic region.

Conclusions: Our results fit with the view that in Uganda socioeconomic characteristic may influence KSHV seropositivity. Conversely, the results fit with the interpretation that in Uganda sexual-behavioral characteristics, if relevant, contribute minimally.

Keywords: Kaposi sarcoma-associated herpesvirus, Uganda, Kaposi sarcoma, Socioeconomic, Principal Components Analysis, Human herpesvirus 8

\section{Background}

Kaposi sarcoma-associated herpesvirus (KSHV) also called Human herpesvirus 8 (HHV-8), discovered in 1994 in Kaposi sarcoma (KS) tissue from an AIDS patient [1], is the infectious cause of KS [2]. In addition to KS, KSHV also is linked to primary effusion lymphoma (PEL), a rare aggressive serous cavity lymphoma [3], and to Castleman's

\footnotetext{
* Correspondence: changjo@umich.edu

${ }^{1}$ Division of Cancer Epidemiology and Genetics, National Cancer Institute,

National Institutes of Health, Department of Health and Human Services, Bethesda, MD, USA

${ }^{3}$ University of Michigan, School of Public Health, Ann Arbor, MI, USA

Full list of author information is available at the end of the article
}

disease, a benign lymphoproliferative disorder [4]. In 2010, KSHV was declared a Group 1 carcinogenic agent, highlighting its public health significance in countries where it is endemic [5].

KSHV seropositivity is highest $(>50-80 \%)$ in equatorial Africa [6,7], including in Uganda, where 1 in every 2 persons is KSHV seropositive by adult age [8,9]. KSHV seropositivity is intermediate (10\%) in Mediterranean Europe [10] and rare $(<3 \%)$ in the North America and Northern Europe [11,12], except among homosexual men in whom up to 1 in every 3 men may be KSHV seropositive, most likely due to transmission via sexual contact

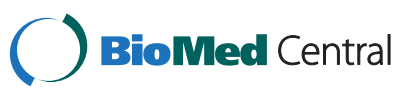


[13]. In KSHV endemic regions, KSHV transmission is associated with casual contact between an infected mother, sibling, or other family member [14-16], particularly in children, and with poor socioeconomic status [14]. Transmission may occur via contact with $\mathrm{KSHV}$ in saliva in crowded poor households [15]. Interestingly, KSHV seropositivity increases with age in endemic regions, indicating that sexual transmission may occur, although this might also be due to virus reactivation later in life increasing detection of antibodies [17]. KSHV seropositivity has been positively associated with some sexual risk factors such as number of marital unions and number of children born in some studies $[8,18]$, but not with other sexual risk factors such as ever had other STIs in other studies $[19,20]$. The validity and/or independence of associations of KSHV seropositivity with sexual, socioeconomic, and family characteristics is uncertain because those findings were based on studies conducted in hospital-based populations [21], individuals with sexually transmitted diseases or commercial sex workers $[18,20,22]$ or selected occupational groups [23], whose results may not be generalized.

We previously showed statistically significant positive association between KSHV seropositivity and male gender, increasing age, low or no formal education, and residence in a KS endemic geographical area in Uganda [8], using data from a nationally representative populationbased sample of adults in Uganda [8,9]. In a follow-up analysis of the same subjects, KSHV seropositivity was positively associated with number of marital unions, number of children born, and inversely associated with having ever used a condom [9], possibly implicating sexual transmission. However, KSHV seropositivity was not associated with human herpes simplex 2 (HSV2), human immunodeficiency virus (HIV) infections and other sexual variables, casting doubt on the significance of heterosexual sexual KSHV transmission in this population. Nonetheless, as this study evaluated only 18 of 97 variables for association with KSHV seropositivity, confounding or nonspecificity of associations could not be excluded [8,23].

In this paper we conducted a principal components analysis (PCA), an agnostic data reduction method that allows us to construct underlying exposure components on the cohort using data from 97 variables collected in the original Uganda HIV/AIDS sero-behavioral survey (UHSBS) [24] in 2004/05 study to evaluate associations with KSHV seropositivity in Uganda.

\section{Results}

We identified three independent principal components (PCs), which were labeled descriptively as Sexual behavioral, Socioeconomic, and Knowledge PCs (Table 1). Variables contributing to the "Sexual behavioral" PC included ever had received blood transfusion, tested for HIV positive, tested for HSV positive, number of children, being currently married, and not using a condom during the last sex intercourse. Variables contributing to the "Socioeconomic" PC included wealth index, non-mud based flooring material, higher education status, owning a radio, telephone, bicycle, or car (ownership of communication device or transportation method), having electricity access, and ownership of durable goods. Variables contributing to the "Knowledge" PC included can people avoid or reduce the chance of getting AIDS by avoid having sex with homosexual, getting mosquito bites, kissing and getting protection from traditional healer.

In unadjusted analyses (Table 2), KHSV seropositivity was significantly associated with Socioeconomic $\left(p_{\text {trend }}=\right.$ $0.0001)$ and Knowledge ( $\left.p_{\text {trend }}=0.012\right)$ PCs, but it was not associated with the Sexual behavioral PC ( $p_{\text {trend }}=$ 0.07). Higher scores on the Socioeconomic and Knowledge PCs were associated with lower KSHV seropositivity. The association of KSHV seropositivity with the Socioeconomic $\left(p_{\text {trend }}=0.002\right)$ and Knowledge $\left(p_{\text {trend }}=0.018\right)$ PCs remained significant when we adjusted for age, sex and geographical area of residence. The category-specific ORs between KSHV seropositivity and the Knowledge and Sexual behavioral, but not Socioeconomic, PCs were substantially attenuated or the effect was reversed in some cases when we adjusted associations for the PCs, suggesting that the crude associations with these PCs were confounded. KSHV seropositivity was significantly associated with the Socioeconomic PC, but not with Knowledge PC when the PCs were entered into a multivariable model that also included age, sex, and geographical region $\left(p_{\text {trend }}=0.038\right)$. When we tested for goodness-of-fit, a multivariable including the Socioeconomic PC fit the data better than models including the Knowledge and Sexual behavioral PCs $(\log$-likelihood $\mathrm{p}<0.0001)$.

\section{Discussion}

We found that in Uganda, where KSHV is highly endemic, KSHV seropositivity was inversely associated with high factor scores on the Socioeconomic and Knowledge PCs, but not with Sexual behavioral PC. The association remained significant when we adjusted for sex, age, and geographical regions, which were considered confounders of KSHV seropositivity in this population [12], suggesting that the findings may be valid.

Our study results are generally consistent with previous studies, which have suggested role of socioeconomic status in KSHV seropositivity in Uganda, based on a study which also used a factor analysis approach [14]. In that study, KSHV seropositivity was inversely associated with low factor scores of maternal and environmental factors, which are surrogates for socioeconomic status. However, that study was based on hospital-based population and relatively limited number of covariates that was available for adjustment. Our results, from a much 
Table 1 Factor loadings from principal components analysis of UHSBS data years in 2004-2005 ${ }^{\mathrm{a}}$

\begin{tabular}{|c|c|c|c|}
\hline \multirow[b]{2}{*}{ Variables } & \multicolumn{3}{|c|}{ Principal components ${ }^{b}$} \\
\hline & Sexual behavioral & Socioeconomic & Knowledge \\
\hline Have you ever had a blood transfusion? & 0.785 & 0.013 & -0.007 \\
\hline Number of children & 0.783 & -0.104 & 0.024 \\
\hline Are you HSV positive? & 0.777 & -0.031 & 0.013 \\
\hline Are you HIV positive? & 0.775 & 0.029 & 0.013 \\
\hline Did you use condom during the last sex intercourse? & 0.731 & -0.066 & 0.050 \\
\hline Are you currently married? & 0.675 & -0.120 & -0.003 \\
\hline Number of lifetime sex partners & 0.496 & 0.038 & 0.001 \\
\hline Occupation & 0.404 & 0.187 & 0.025 \\
\hline Wealth Index & -0.049 & 0.748 & 0.043 \\
\hline Use mud as floor material? & -0.126 & 0.701 & 0.002 \\
\hline Education level & -0.176 & 0.594 & -0.009 \\
\hline Ownership of communication device & -0.027 & 0.522 & 0.068 \\
\hline Ownership of durable good? & -0.029 & 0.505 & 0.043 \\
\hline Electricity access? & -0.127 & 0.487 & 0.017 \\
\hline What type of toilet does your household have? & -0.090 & 0.457 & 0.011 \\
\hline Ethnicity-Baganda & 0.031 & 0.435 & -0.062 \\
\hline Use of bednet? & -0.047 & 0.402 & 0.014 \\
\hline Would you buy vegetables from a vendor had AIDS? & 0.053 & 0.401 & -0.058 \\
\hline $\begin{array}{l}\text { Have you heard of any drugs that can PROLONG THE LIFE of a } \\
\text { person who has the virus? }\end{array}$ & 0.165 & 0.383 & -0.068 \\
\hline $\begin{array}{l}\text { Are there any special drugs that a doctor or nurse can give to } \\
\text { pregnant women infected with AIDS to reduce the risk of transmission? }\end{array}$ & 0.099 & 0.370 & -0.051 \\
\hline Should a HIV-infected female teacher be allowed to teach in school? & 0.128 & 0.362 & -0.057 \\
\hline Source of water? & -0.015 & 0.352 & -0.008 \\
\hline${ }^{\mathrm{C}}$ By avoiding sex with homosexual? & 0.022 & -0.140 & 0.909 \\
\hline${ }^{\circ}$ By avoiding mosquito bites? & -0.016 & 0.120 & -0.798 \\
\hline 'By avoiding kissing? & -0.031 & 0.098 & -0.845 \\
\hline${ }^{\mathrm{C} B y}$ protection from traditional healer & -0.030 & 0.149 & -0.898 \\
\hline By avoiding partners who have many partners? & -0.020 & -0.075 & 0.687 \\
\hline By avoiding sex prostitute? & 0.035 & -0.068 & 0.682 \\
\hline By avoiding blood transfusions? & -0.047 & 0.055 & 0.587 \\
\hline By asking partner to get tested? & -0.010 & 0.011 & 0.495 \\
\hline By avoiding injections? & -0.054 & 0.021 & 0.446 \\
\hline By limit number of sex partners? & 0.085 & 0.007 & 0.418 \\
\hline By avoid sharing razor blades with AIDS patients? & -0.151 & 0.085 & 0.311 \\
\hline Are you a Christian? & -0.020 & -0.255 & 0.051 \\
\hline Are you a Muslim? & 0.001 & 0.265 & -0.060 \\
\hline Are you currently divorced? & 0.048 & -0.031 & 0.001 \\
\hline
\end{tabular}

${ }^{a}$ Only showing 35 out of 74 variables; ${ }^{b}$ These components were labeled descriptively to reflect variables with high component loadings; ${ }^{\mathrm{c}}$ Can people avoid or reduce the chance of getting AIDS by these routes.

larger population-based sample that is geographically representative of the Ugandan population, confirm the role of socioeconomic status in KSHV seropositivity in Uganda. The null association with the Sexual behavioral PC does not support an important role of sexual behavior on
KSHV seropostivity in the general population in Uganda. This conclusion is different from the one reached by Shebl et al. [9] Although KSHV seropositivity was not associated with HIV or HSV2 infections, with lifetime number of sexual partners, having at least one sexually transmitted 
Table 2 Seroprevalence and association between KSHV seropositivity and Principal components (PCs) by quartile

\begin{tabular}{|c|c|c|c|c|c|c|c|c|}
\hline \multirow[t]{2}{*}{ Principal components } & \multicolumn{2}{|c|}{ KSHV seropositivity } & \multicolumn{2}{|c|}{ Univariate } & \multicolumn{2}{|c|}{ Multivariable $^{a}$} & \multicolumn{2}{|c|}{ Full multivariable model } \\
\hline & $\%$ & $95 \% \mathrm{Cl}$ & OR & $95 \% \mathrm{Cl}$ & OR & $95 \% \mathrm{Cl}$ & OR & $95 \% \mathrm{Cl}$ \\
\hline \multicolumn{9}{|l|}{ Sexual behavioral } \\
\hline $1^{\text {st }}$ quartile & 49.2 & $50.0,54.4$ & Ref & Ref & Ref & Ref & Ref & Ref \\
\hline $2^{\text {nd }}$ quartile & 56.6 & $51.5,61.6$ & 1.35 & $1.01,1.80$ & 1.11 & $0.82,1.51$ & 1.08 & $0.79,1.46$ \\
\hline $3^{\text {rd }}$ quartile & 56.7 & $51.9,61.7$ & 1.36 & $1.02,1.80$ & 1.06 & $0.77,1.45$ & 1.02 & $0.73,1.42$ \\
\hline $4^{\text {th }}$ quartile & 56.2 & $51.5,60.9$ & 1.33 & $1.01,1.73$ & 0.95 & $0.69,1.32$ & 0.96 & $0.68,1.35$ \\
\hline$P$ value for heterogeneity & 0.106 & & 0.10 & & 0.74 & & 0.89 & \\
\hline$P$ value for trend & & & 0.066 & & 0.61 & & 0.58 & \\
\hline \multicolumn{9}{|l|}{ Socioeconomic } \\
\hline $1^{\text {st }}$ quartile & 61.6 & $57.3,65.9$ & Ref & Ref & Ref & Ref & Ref & Ref \\
\hline $2^{\text {nd }}$ quartile & 56.8 & $52.2,61.4$ & 0.82 & $0.65,1.05$ & 0.85 & $0.67,1.08$ & 0.87 & $0.67,1.14$ \\
\hline $3^{\text {rd }}$ quartile & 48.8 & $43.7,53.9$ & 0.60 & $0.46,0.78$ & 0.61 & $0.47,0.81$ & 0.68 & $0.49,0.92$ \\
\hline $4^{\text {th }}$ quartile & 50.6 & $45.4,55.8$ & 0.64 & $0.49,0.84$ & 0.67 & $0.50,0.91$ & 0.78 & $0.54,1.13$ \\
\hline$P$ value for heterogeneity & $0.0003^{*}$ & & $0.0004^{*}$ & & 0.005 & & 0.095 & \\
\hline$P$ value for trend & & & $0.0001^{*}$ & & $0.002^{*}$ & & $0.037^{*}$ & \\
\hline \multicolumn{9}{|l|}{ Knowledge } \\
\hline $1^{\text {st }}$ quartile & 59.9 & $55.5,64.4$ & Ref & Ref & Ref & Ref & Ref & Ref \\
\hline $2^{\text {nd }}$ quartile & 55.5 & $50.0,60.9$ & 0.83 & $0.63,1.11$ & 0.85 & $0.64,1.14$ & 1.00 & $0.74,1.36$ \\
\hline $3^{\text {rd }}$ quartile & 47.7 & $42.8,52.5$ & 0.61 & $0.47,0.79$ & 0.63 & $0.48,0.82$ & 0.76 & $0.57,1.02$ \\
\hline $4^{\text {th }}$ quartile & 54.4 & $49.8,58.9$ & 0.80 & $0.62,1.02$ & 0.80 & $0.63,1.03$ & 0.96 & $0.74,1.25$ \\
\hline$P$ value for heterogeneity & $0.004^{*}$ & & $0.003^{*}$ & & $0.006^{*}$ & & 0.18 & \\
\hline$P$ value for trend & & & $0.012^{*}$ & & $0.018^{*}$ & & 0.49 & \\
\hline
\end{tabular}

a. Adjusted for age, sex, geographical region; ${ }^{\text {b. }}$ Adjusted for age, sex, and geographical region and other $\mathrm{PCs}$; $p$-value $<0.0$.

disease were unrelated to KSHV seropositivity, it was inversely associated with ever use of condom use and positively associated with being married and with each additional child born, suggested a possible, albeit, small role of sexual transmission. Our study found a marginal association between the Sexual behavior PC and KSHV seropositivity in crude analyses, but the association disappeared after adjusting for the other PCs, suggesting that the association detected with sexual variables may be due to confounding by other poorly understood socioeconomic factors.

While our results should not be interpreted as proving the lack of KSHV transmission via sexual contact, they support conclusions reached in other studies that that sexual transmission of KSHV is not a major source of infection in the general population $[20,25,26]$. KSHV seropositivity varies substantially by geography at a global as well local level. For example, de Sanjose and colleagues [26] observed significant variation in KSHV seroprevalence from $3.8 \%$ in Spain to $46 \%$ in Nigeria among women participating in a large international study conducted by the International Agency for Research on Cancer. KSHV seropositivity is lower in wealthier countries in Africa, such as South Africa, and higher in poorer countries, such as Uganda [25-27]. Within countries, KSHV seropositivity is higher in rural areas but lower in urban areas $[28,29]$. The biological basis of this variation is presently unclear to us. Our results suggest that variation in socioeconomic status may play a role in the geographical variation of KSHV seropositivity [14,26,28]. We previously hypothesized that infection with stool parasites, which is highly prevalent in poor countries, may play a role in KSHV transmission [30,31]. Findings by Lin et al. that KS patients attending the Uganda Cancer Institute were more likely to have a higher carriage of Strongyloides parasites than patients with other cancers treated at the same hospital [30] provide some support for the hypothesis. The hypothesis was also supported by a study of mother-infant pairs in Uganda [31], which reported that detection of malaria parasitaemia, hookworm and Mansonella perstans in stool was associated KSHV seropositivity. However, KSHV was not associated with some other parasites evaluated in the same study, including Schistosoma mansoni, Strongyloides stercoralis, Trichuris trichiura, Ascaris lumbricoides and Trichostrongylus species, suggesting that the role of parasites in the geographical variation of KSHV seropositivity requires further evaluation. 


\section{Strengths and limitations}

The strengths of our study include having detailed data on a nationally representative sample, which enabled us to use PCA methods to evaluate associations with KSHV seropositivity. Exclusion of variables where prior studies indicated significant associations enabled us to confirm those previous associations after taking into account all available data. PCA has the ability to identify independent factors that explain the maximum amount of mutual correlation [32]. However, our findings should be interpreted with caution. First, while the PCA methods offer a parsimonious way to transform many correlated variables into a few uncorrelated variables, it may mask relevant associations. For instance, some sexual behavioral variables such as ever used condom from the last sex intercourse or number of children born were found to be associated with KSHV seropositivity [9], but PCA does not reveal this association. Moreover, since PCA is summing up across errors in data collection, data entry and laboratory testing, some contradictory patterns can be found compared to previous findings. Second, our data are cross-sectional; therefore, it is not possible to determine the direction of causality. Third, KSHV serology is imperfect [33], thus, misclassification of results, although it would be random, is possible.

\section{Conclusions}

To summarize, we report a significant association between low socioeconomic status and KSHV seropositivity. Sexual behavioral and Knowledge PCs were unrelated to KSHV seropositivity. Future work is needed to better understand how socioeconomic exposures influence KSHV transmission in countries where KSHV and KS are endemic.

\section{Materials and methods Ethical approval}

The Uganda Virus Research Institute (UVRI) Science Ethics Committee and the National Council of Science and Technology in Uganda and from the Centers for Disease Control and Prevention (CDC, Atlanta, Georgia, USA) gave ethical approval to conduct the study.

\section{Study population}

Details of this study have been previously reported $[8,9,34,35]$. Briefly, the study was based on a subset of data from the original 19,656 Ugandans aged 15-59 years enrolled the UHSBS in 2004-2005 to investigate national and subnational patterns of HIV/AIDS in Uganda [34,35]. The UHSBS used a two-stage cluster probability sample design to obtain a nationally representative sample of adults. In the first stage, 417 clusters were selected from census enumeration areas of the 2002 Uganda National Census [36]. In the second stage, 25 households were randomly selected per cluster. All adult residents in the household were invited to participate, for a total sample size of 10,437 individuals.

The KSHV studies are based on 2,681 individuals randomly selected from the original UHSBS sample and tested for KHSV serologically [8,9]. Detailed descriptions of the Uganda cohort and blood sampling technique have been described in previous studies [8,9].

\section{KSHV serology and testing}

KSHV serology was performed at UVRI in Uganda using synthetic peptides encoded by K8.1 and orf65 viral genes manufactured at the CDC Herpes Virology Laboratory in Atlanta [37,38]. The qualities of KSHV serology at UVRI and the CDC were comparable, based on parallel testing of a panel of well characterized samples subjects with KS, asymptomatic Ugandans, and HIV positive and negative Caucasians provided by the National Cancer Institute (Spearman's rank correlation coefficients for optical density $(\mathrm{OD})$ values $=0.86$ for $\mathrm{K} 8.1$ and $\mathrm{OD}=0.78$ for orf65, both $p<0.001)$. Although KSHV serology remains imperfect, the combined assays have a sensitivity of about 93\% [38] and a specificity of about 98\% [39] in African samples. KSHV results were categorized as positive when the adjusted K8.1 OD was $>0.7$ or $0.5-0.7$ and the adjusted orf65 OD was $>2.5$, negative when the adjusted K8.1 OD was $0.5-0.7$ and the adjusted orf65 OD was $\leq 2.5$, and indeterminate when the adjusted K8.1 OD was 0.5-0.7 and the orf65 OD was $<2.5$.

\section{Data and variables}

Detailed analyses of KSHV seropositivity patterns have been assessed and described in previous studies $[8,9]$. To observe the complete pattern of KSHV seropositivity in Uganda, this study included all questions were asked in the UHSBS including questions with knowledge and attitudes on HIV/AIDS and additional household questions, which was not elicited described in previous studies $[8,9,34,35]$.

The data included information from household (18 variables) and individual (76 variables) questionnaires and from results of laboratory tests (3 variables: HIV, HSV2 (all subjects) and hepatitis B virus (HBV) (available on the same random $1 / 3$ subsample of subjects)). The household questionnaire elicited information on ownership of durable goods, car, motorcycle or bicycle, television, mobile phone and landline phone, mosquito bed net, source of drinking water (surface, well/public, well/private, piped/ private), type of material used to build the floor, source of electricity, and type of toilet used (none, uncovered pit, covered pit, or flush toilet). The individual questionnaire elicited information on demographic information, knowledge and attitudes about how HIV may be transmitted or not and their knowledge about correct and incorrect 
routes of HIV/AIDS, their attitudes toward people who may have HIV/AIDS. For example, demographic information includes level of education attained, current occupation, ethnicity, religion, number of children born, and current marital status. Questions about knowledge and attitudes about HIV transmission include "can people avoid or reduce the chances of getting AIDS or the virus that causes AIDS by avoiding mosquito bites?", or "can people avoid or reduce the chances of getting AIDS or the virus that causes AIDS by using condom during sex?"; questions about their attitudes toward people who may have HIV/AIDS include "would you take care of a relative who is living with AIDS?", or "should a HIV-infected female teacher be allowed to teach in school?".

\section{Statistical methods}

Principal Components are linear combinations of the input variables and explain as much of the variation in the data as possible [32]. Large positive or negative factor loadings indicate the variable that is more representative in that component. Factor loadings with a magnitude at least 0.3 were used to describe the component.

Statistical analyses were performed in SAS version 9.2 using PROC FACTOR procedure (SAS Institute, Cary, NC, USA). Analysis utilized available data from 97 variables collected during the UHSBS. PCA was utilized to transform the 97 correlated variables in the dataset into a smaller set of uncorrelated variables (Figure 1) [32]. Because age, gender, and geographic region were previously shown to be significantly associated with KSHV seropositivity [22], they were excluded from the PCA. To avoid redundancy, Pearson correlations of all pairs of 94 variables were computed, and when the correlation coefficients were greater than 0.90 , only one of the two variables was chosen to be included in the PCA. The chosen variable was the one with less missing values. In addition, if the sample size were similar, variable with less correlation was selected. This resulted in exclusion of 21 variables. Thus, 76 representative variables were retained for PCA. The PCs were identified, based on the patterns of the Scree plots. Three PCs were identified
97 variables including questions about sexual behaviors, socioeconomic status, sexual knowledge, and environmental exposure

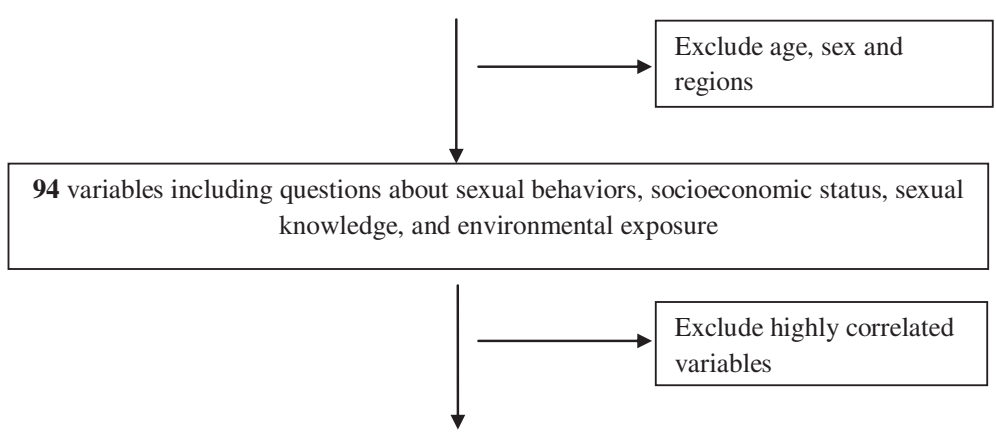

76 variables including questions about sexual behaviors, socioeconomic status, sexual knowledge, and environmental exposure

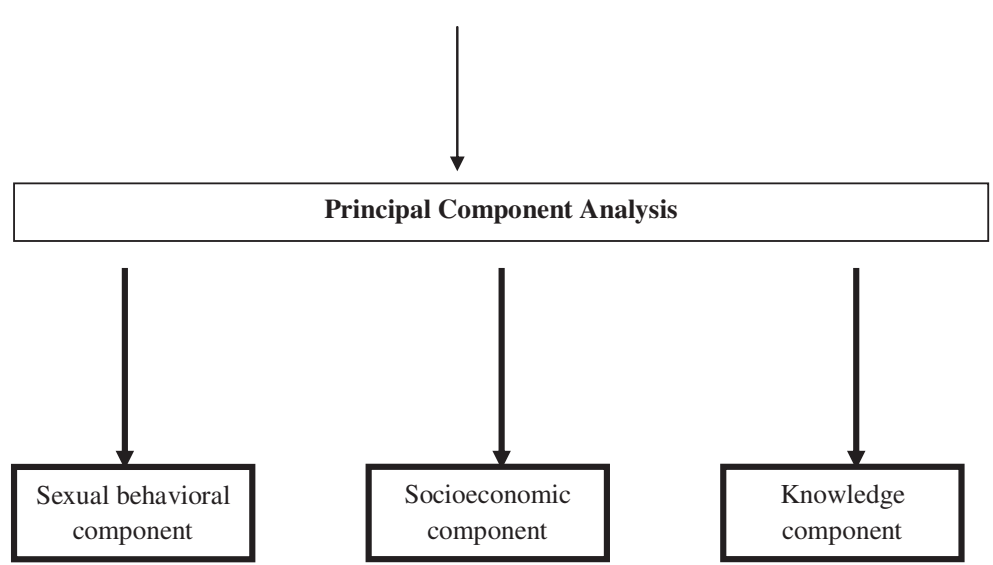

Figure 1 Flow chart showing data reduction approach applied to household- and individual-questionnaire variables and laboratory results during principal components analysis. 
from and the resulting PCs were transformed into uncorrelated through orthogonal rotation (varimax). The PCs were labeled descriptively based on the variables with high factor loadings $(>0.3)$.

The association between PCs and KSHV seropositivity was evaluated by entering PCs, PC scores were computed for each individual and were divided into quartiles to create categorical variables. The odds ratios (ORs) and $95 \%$ confidence intervals (CIs) were used to estimate the association between KSHV seropositivity and the PCs. The logistic regression analyses were weighted for the sample and accounted for the cluster sampling of the UHSBS using the SAS survey procedure PROC SURVEYLOGISTIC. Age, gender, and geographic location, which were not included in the derivation of PCs but were considered $a$ priori established risk factors for KSHV seropositivity [7], were entered as covariates in logistic regression to adjust for potential confounding of the association between PCs and KSHV seropositivity. 2-sided $p$-values were obtained using the Rao-Scott tests [40] were considered statistically significant if less than 0.05 .

\section{Consent}

Written informed consent was obtained for the patient for publication of this report.

\begin{abstract}
Abbreviations
KSHV: Kaposi sarcoma-associated herpesvirus; HHV8: Human herpesvirus 8; PCA: Principal components analysis; PC: Principal component; KS: Kaposi sarcoma; PEL: Primary effusion lymphoma; HSV2: Herpes simplex 2; HIV: Human immunodeficiency virus; UHSBS: Uganda HIV/AIDS serobehavioral survey; UVRI: Uganda virus research institute; CDC: Centers for disease control and prevention; OD: Optical density OD; HBV: Hepatitis B virus; OR: Odds ratios; Cl: Confidence interval.
\end{abstract}

\section{Competing interests}

The authors declare that they have no competing interests.

\section{Authors' contributions}

All authors listed have contributed to the project. JC conducted the data analysis, interpreted data, and drafted the manuscript. FS helped design the study, supervised data analysis, and interpreted data. RP and BG supervised statistical analyses and interpreted data. BB performed KSHV serology and interpreted data. SM conceived the study, directed its implementation, interpreted data, and edited the manuscript. All authors reviewed, revised, and approved the manuscript.

\section{Acknowledgements \\ We thank Sandra Brown (Infections and Immunoepidemiology Branch, National Cancer Institute, Bethesda, MD) for computerizing KSHV results from the feasibility study, Drs. Wilford Kirungi, Joshua Musinguzi and Alex Opio of the Ministry of Health, Kampala, Uganda, the survey teams, laboratory staff, data managers, analysts for UHSBS 2004/05; the Uganda Bureau of Statistics, the Joint United Nations Program on HIV/AIDS; ORC Macro and the World Health Organization, United States Agency for International Development, CDC who sponsored and/or implemented, and supervised the UHSBS 2004/05}

\section{Funding}

The work was supported by the Intramural Research Program of the Division of Cancer Epidemiology and Genetics, National Cancer Institute (NCl), National Institutes of Health, Department of Health and Human Services (contract HHSN2612009004060P and Support Services contract NO2-CP-
31003) and by an Inter-Agency Agreement between $\mathrm{NCl}$ and the Centers for Disease Control and Prevention (IAA Y1CP903801). Joanne Chang was supported by the NCI Intramural Research Program and the University of Michigan School of Public Health (grant R25 CA112383). The content is the responsibility of the authors alone and does not necessarily reflect the views or the policies of the United States Department of Health and Human Services or participating entities.

\section{Author details}

'Division of Cancer Epidemiology and Genetics, National Cancer Institute, National Institutes of Health, Department of Health and Human Services, Bethesda, MD, USA. ${ }^{2}$ Uganda Virus Research Institute, Entebbe, Uganda. ${ }^{3}$ University of Michigan, School of Public Health, Ann Arbor, MI, USA.

${ }^{4}$ Currently at Yale School of Public Health, New Haven, CT, USA.

Received: 22 October 2012 Accepted: 14 January 2013

Published: 16 January 2013

\section{References}

1. Chang Y, Cesarman E, Pessin MS, Lee F, Culpepper J, Knowles DM, Moore PS: Identification of herpesvirus-like DNA sequences in AIDS-associated Kaposi's sarcoma. Science 1994, 266(5192):1865-1869.

2. Martin JN: Kaposi sarcoma-associated herpesvirus/human herpesvirus 8 and Kaposi sarcoma. Adv Dent Res 2011, 23(1):76-78

3. Cesarman E, Chang Y, Moore PS, Said JW, Knowles DM: Kaposi's sarcomaassociated herpesvirus-like DNA sequences in AIDS-related body-cavitybased lymphomas. N Engl J Med 1995, 332(18):1186-1191.

4. Soulier J, Grollet L, Oksenhendler E, Cacoub P, Cazals-Hatem D, Babinet P, D’Agay MF, Clauvel JP, Raphael M, Degos L: Kaposi's sarcoma-associated herpesvirus-like DNA sequences in multicentric Castleman's disease. Blood 1995, 86(4):1276-1280.

5. IARC Monographs on the Evaluation of Carcinogenic Risks to Humans: Vol 100B, A Review of Human Carcinogen: Biological Agents. Lyon, France: International Agency for Research on Cancer; 2012.

6. Dukers NH, Rezza G: Human herpesvirus 8 epidemiology: what we do and do not know. AIDS 2003, 17(12):1717-1730.

7. Dedicoat M, Newton R: Review of the distribution of Kaposi's sarcomaassociated herpesvirus (KSHV) in Africa in relation to the incidence of Kaposi's sarcoma. Br J Cancer 2003, 88(1):1-3.

8. Biryahwaho B, Dollard SC, Pfeiffer RM, Shebl FM, Munuo S, Amin MM, Hladik W, Parsons R, Mbulaiteye SM: Sex and geographic patterns of human herpesvirus 8 infection in a nationally representative population-based sample in Uganda. J Infect Dis 2010, 202(9):1347-1353.

9. Shebl FM, Dollard SC, Pfeiffer RM, Biryahwaho B, Amin MM, Munuo SS, Hladik W, Parsons R, Graubard BI, Mbulaiteye SM: Human herpesvirus 8 seropositivity among sexually active adults in Uganda. PLoS One 2012, 6(6):e21286.

10. Serraino $D$, Toma L, Andreoni M, Butto S, Tchangmena O, Sarmati L, Monini $P$, Franceschi S, Ensoli B, Rezza G: A seroprevalence study of human herpesvirus type 8 (HHV8) in eastern and Central Africa and in the Mediterranean area. Eur J Epidemiol 2001, 17(9):871-876.

11. Engels EA, Clark E, Aledort LM, Goedert JJ, Whitby D: Kaposi's sarcomaassociated herpesvirus infection in elderly Jews and non-Jews from New York City. Int J Epidemiol 2002, 31(5):946-950.

12. Engels EA, Atkinson JO, Graubard BI, McQuillan GM, Gamache C, Mbisa G, Cohn S, Whitby D, Goedert JJ: Risk factors for human herpesvirus 8 infection among adults in the United States and evidence for sexual transmission. J Infect Dis 2007, 196(2):199-207.

13. Mbulaiteye SM, Atkinson JO, Whitby D, Wohl DA, Gallant JE, Royal S, Goedert JJ, Rabkin CS: Risk factors for human herpesvirus 8 seropositivity in the AIDS Cancer Cohort Study. J Clin Virol 2006, 35(4):442-449.

14. Mbulaiteye SM, Biggar RJ, Pfeiffer RM, Bakaki PM, Gamache C, Owor AM, Katongole-Mbidde E, Ndugwa CM, Goedert JJ, Whitby D, Water Engels EA: Water, socioeconomic factors, and human herpesvirus 8 infection in Ugandan children and their mothers. J Acquir Immune Defic Syndr 2005, 38(4):474-479.

15. Mbulaiteye SM, Pfeiffer RM, Engels EA, Marshall V, Bakaki PM, Owor AM, Ndugwa CM, Katongole-Mbidde E, Goedert JJ, Biggar RJ, Whitby D: Detection of kaposi sarcoma-associated herpesvirus DNA in saliva and buffy-coat samples from children with sickle cell disease in Uganda. $J$ Infect Dis 2004, 190(8):1382-1386. 
16. Mbulaiteye SM, Pfeiffer RM, Whitby D, Brubaker GR, Shao J, Biggar RJ: Human herpesvirus 8 infection within families in rural Tanzania. J Infect Dis 2003, 187(11):1780-1785.

17. Butler LM, Were WA, Balinandi S, Downing R, Dollard S, Neilands TB, Gupta S, Rotherford GW, Mermin J: Human Herpesvirus 8 Infection in Children and Adults in a Population-based Study in Rural Uganda. J Infect Dis 2011, 203(5):625-634.

18. Eltom MA, Mbulaiteye SM, Dada AJ, Whitby D, Biggar RJ: Transmission of human herpesvirus 8 by sexual activity among adults in Lagos, Nigeria. AIDS 2002, 16(18):2473-2478.

19. Wawer MJ, Eng SM, Serwadda D, Sewankambo NK, Kiwanuka N, Li C, Gray $\mathrm{RH}$ : Prevalence of Kaposi sarcoma-associated herpesvirus compared with selected sexually transmitted diseases in adolescents and young adults in rural Rakai District, Uganda. Sex Transm Dis 2001, 28(2):77-81.

20. Malope BI, MacPhail P, Mbisa G, MacPhail C, Stein L, Ratshikhopha EM, Ndhlovu L, Sitas F, Whitby D: No evidence of sexual transmission of Kaposi's sarcoma herpes virus in a heterosexual South African population. AIDS 2008, 22(4):519-526.

21. Mbulaiteye SM, Biggar RJ, Bakaki PM, Pfeiffer RM, Whitby D, Owor AM Katongole-Mbidde E, Goedert JJ, Ndugwa CM, Engels EA: Human herpesvirus 8 infection and transfusion history in children with sickle-cell disease in Uganda. J Natl Cancer Inst 2003, 95(17):1330-1335.

22. Lavreys L, Chohan B, Ashley R, Richardson BA, Corey L, Mandaliya K, Ndinya-Achola JO, Kreiss JK: Human herpesvirus 8: seroprevalence and correlates in prostitutes in Mombasa, Kenya. J Infect Dis 2003, 187(3):359-363.

23. Baeten JM, Chohan BH, Lavreys L, Rakwar JP, Ashley R, Richardson BA, Mandaliya K, Bwayo JJ, Kreiss JK: Correlates of human herpesvirus 8 seropositivity among heterosexual men in Kenya. AIDS 2002, 16(15):2073-2078.

24. Ministry of Health (MOH) [Uganda] and ORC Macro: Uganda HIV/AIDS SeroBehavioural Survey 2004-2005. Calverton, MD: Ministry of Health and ORC Macro; 2006.

25. Mbulaiteye SM, Goedert JJ: Transmission of Kaposi sarcoma-associated herpesvirus in sub-Saharan Africa. AIDS 2008, 22(4):535-537.

26. de Sanjose S, Mbisa G, Perez-Alvarez S, Benavente Y, Sukvirach S, Hieu NT, Shin HR, Anh PT, Thomas J, Lazcano E, Matos E, Herrero R, Munoz N, Molano M, Franceschi S, Whitby D: Geographic variation in the prevalence of Kaposi sarcoma-associated herpesvirus and risk factors for transmission. J Infect Dis 2009, 199(10):1449-1456.

27. Dollard SC, Butler LM, Jones AM, Mermin JH, Chidzonga M, Chipato T, Shiboski CH, Brander C, Mosam A, Kiepiela P, Hladik W, Martin JN: Substantial regional differences in human herpesvirus 8 seroprevalence in sub-Saharan Africa: insights on the origin of the "Kaposi's sarcoma belt". Int J Cancer 2010, 127(10):2395-2401.

28. Pfeiffer RM, Wheeler WA, Mbisa G, Whitby D, Goedert JJ, de The G, Mbulaiteye SM: Geographic heterogeneity of prevalence of the human herpesvirus 8 in sub-Saharan Africa: clues about etiology. Ann Epidemiol 2010, 20(12):958-963.

29. Mbulaiteye SM, Pfeiffer RM, Dolan B, Tsang VC, Noh J, Mikhail NN, Abdel-Hamid M, Hashem M, Whitby D, Thomas Strickland G, Goedert JJ: Seroprevalence and risk factors for human herpesvirus 8 infection, rural Egypt. Emerg Infect Dis 2008, 14(4):586-591.

30. Lin CJ, Katongole-Mbidde E, Byekwaso T, Orem J, Rabkin CS, Mbulaiteye SM: Intestinal parasites in Kaposi sarcoma patients in Uganda: indication of shared risk factors or etiologic association. AmJTrop Med Hyg 2008, 78(3):409-412.

31. Wakeham K, Webb EL, Sebina I, Muhangi L, Miley W, Johnson WT, Ndibazza J, Elliott AM, Whitby D, Newton R: Parasite infection is associated with Kaposi's sarcoma associated herpesvirus (KSHV) in Ugandan women. Infect Agent Cancer 2011, 6(1):15.

32. Johnstone IM, Lu AY: On Consistency and Sparsity for Principal Components Analysis in High Dimensions. J Am Stat Assoc 2009, 104(486):682-693.

33. Rabkin CS, Schulz TF, Whitby D, Lennette ET, Magpantay LI, Chatlynne L, Biggar RJ: Interassay correlation of human herpesvirus 8 serologic tests. HHV-8 Interlaboratory Collaborative Group. J Infect Dis 1998, 178(2):304-309.

34. Mermin J, Musinguzi J, Opio A, Kirungi W, Ekwaru JP, Hladik W, Kaharuza F, Downing $\mathrm{R}$, Bunnell R: Risk factors for recent HIV infection in Uganda. JAMA 2008, 300(5):540-549.
35. Bunnell R, Opio A, Musinguzi J, Kirungi W, Ekwaru P, Mishra V, Hladik W, Kafuko J, Madraa E, Mermin J: HIV transmission risk behavior among HIVinfected adults in Uganda: results of a nationally representative survey. AIDS 2008, 22(5):617-624.

36. Uganda Bureau of Statistics: The 2002 Uganda population and housing census, population size and distribution. Kampala: UBS; 2006. Available from: http://www.ubos.org/onlinefiles/uploads/ubos/pdf\%20documents/2002\% 20CensusPopnSizeGrowthAnalyticalReport.pdf [accessed 15 July 2011]

37. Pau CP, Lam LL, Spira TJ, Black JB, Stewart JA, Pellett PE, Respess RA: Mapping and serodiagnostic application of a dominant epitope within the human herpesvirus 8 ORF 65-encoded protein. J Clin Microbiol 1998, 36(6):1574-1577.

38. Spira TJ, Lam L, Dollard SC, Meng YX, Pau CP, Black JB, Burns D, Cooper B, Hamid M, Huong J, Kite-Powell K, Pellett PE: Comparison of serologic assays and PCR for diagnosis of human herpesvirus 8 infection. J Clin Microbiol 2000, 38(6):2174-2180.

39. Hladik W, Dollard SC, Mermin J, Fowlkes AL, Downing R, Amin MM, Banage F, Nzaro E, Kataaha P, Dondero TJ, Pellett PE, Lackritz EM: Transmission of human herpesvirus 8 by blood transfusion. N Engl J Med 2006, 355(13):1331-1338

40. Rao JNK, Scott AJ: The analysis of categorical data from complex surveys: Chi-squared test for goodness of fit and independence in two-way tables. J Am Stat Assoc 1981, 76:221-230.

doi:10.1186/1750-9378-8-3

Cite this article as: Chang et al:: A population-based study of Kaposi Sarcoma-associated herpesvirus seropositivity in Uganda using principal components analysis. Infectious Agents and Cancer 2013 8:3.

\section{Submit your next manuscript to BioMed Central and take full advantage of:}

- Convenient online submission

- Thorough peer review

- No space constraints or color figure charges

- Immediate publication on acceptance

- Inclusion in PubMed, CAS, Scopus and Google Scholar

- Research which is freely available for redistribution 